\title{
Reaching all through Open and Distance Learning in Tanzania
}

\author{
Mwilongo Kardo, J. \\ Mzumbe University - Dar es Salaam Campus College,P.O. Box 20266, Dar es Salaam, Tanzania \\ E-mail: kmwilongo@mzumbe.ac.tz
}

\begin{abstract}
The rapid development of Information and Communication Technologies (ICTs) and the move towards more knowledge-intensive, interdependent and internationalized societies create new challenges and opportunities for the design and delivery of distance education. There are three reasons for disseminating distance education to all societies; vis-à-vis geographical isolation, social isolation and disadvantaged groups. The emergence of the internet and related networks like the World Wide Web and Web 2.0, have had and will increasingly have radical effect on the transformation of education and training in all sectors. The use of innovative teaching and learning methods helps to sustain student's interest and make the learning process more productive and interesting. The techniques that can be adopted are: the use of internet through which different search engines and subject based information gateways can be used to supplement teaching/learning resources; computerassisted learning and web-based learning which includes virtual laboratories, discussion forum, chat, audiovisual presentation, moodling and tutorials. The Ministry of Education and Vocational Training and its education agencies have to review the curriculum and establish centers at district, municipal or at ward level through which open and distance learning can be accessed by the majority. Also, they have the role of ensuring that the facilities used for the programme are user-friendly to learners and particularly those with physical disabilities. However, quality assurance unit incorporating curriculum developers needs to be in place for monitoring and evaluation of the resources, ICT facilities, courses and programmes offered and the learning content, the staff, technology, learning methods and services.
\end{abstract}

Keywords: Distance learning, Education, ICT, e-learning

\section{Introduction}

The rapid development of Information and Communication Technologies (ICTs) and the move towards more knowledge intensive, interdependent and internationalized societies create new challenges and opportunities for the design and delivery of education. ICTs open up new horizons for progress and the exchange of creativity and intercultural dialogue (UNESCO, 2002). Historically, the geographic isolation of learners from educational institutions has been the prime motivation for developing distance learning programs. The early distance learning systems relied primarily on printed materials for instruction. Correspondence courses have been the most common delivery method of course materials to distant and out of school learners (Natarajan, 2005).

The emergence of the internet and related networks such as the World Wide Web and Web 2.0 have had and will increasingly have radical effect on the transformation of the process of teaching and learning to all sectors. The growth of television, telecommunication, videotape, audio teleconferencing, audio graphics conferencing and video conferencing allowed linking the learners and instructors who are geographically isolated. The use of innovative teaching and learning methods helps to sustain learner's interest and make the learning process more effective and interesting. The impact is already significant in all developed countries, and the great majority of developing countries are, despite difficulties and fears seeking to take part in the emerging global educational community. The web offers a worldwide forum in which to teach courses that can be dynamically updated in ways never possible before. Each student has an enormous range of resources available, free from limitations of time and space. There remains considerable work to be done concerning searching and evaluating techniques for quality assurance of these resources for learners and teachers alike. The resources are reconfiguring the ways in which students learn, and new approaches to networked learning are evolving (UNESCO, 2011).

The geographical isolation, social isolation, vulnerable and disadvantaged groups are the three main reasons to disseminate distance education to all societies. People may be geographically isolated because of distance, landscape, or undeveloped communication systems. People can become socially isolated for a number of reasons; mostly it is because they are disadvantaged in some way, financial, physical, emotional, or because of family circumstances $(\mathrm{OECD}$, 2007). Distance learning has been moving very fast from correspondence education to online education or web-based delivery of education leading to the emerging of new types of teaching and learning technologies at an ever-accelerating pace.

The integration of new types of educational technologies, technological development, globalization and massification allows flexible teaching and learning, increased potential for access and interaction between learning resources and the clientele at broader perspectives (Thomas, 1995). It has widened the scope by including online education, online courses, virtual courses and virtual libraries. Learning becomes more self- 
directed, collaborative, integrates clientele life and work, and more resource-based with an everlasting access and usage of information at all the times and space. Learning shifts from know what to knowing how, how to learn, how to secure information, evaluate for quality assurance; use it, and how to relate to a changing society. The new emphasis will be on how to reach all the society (Natarajan, 2005).

Open and distance learning has existed for about one hundred years in the more developed regions and for one or two generations in the developing regions. In the high population countries of the developing world, open and distance learning has been seen to offer very significant opportunities for education and training. Lack of infrastructure and professional competence in open and distance learning remains important barriers. Nevertheless, these forms of educational delivery have come to stay, and many countries are looking at open and distance learning as a major strategy for expanding access, raising quality and ensuring cost-effectiveness (MQA, 2011).

Sub-Saharan Africa is one of the regions where the "knowledge gap" between North and South takes on its most dramatic character. Here, open and distance learning has been mainly used to widen access to basic education and to maintain and improve quality in the conventional education system, particularly through inservice training of teachers. For example, UNESCO was involved in the in-service training of all of Botswana's unqualified teachers in the late 1960s and 1970s. Open and distance learning has also been used in non-formal education and community development by national and international organizations (Ololube, et, al., 2007).

Open and distance learning in Tanzania is organized through the Distance Education Association of Tanzania (DEATA), a national association established in December 1992. Its membership is currently made up of the Ministry of Education and Vocational Training, the Open University of Tanzania, the University of Dar es Salaam, the Vocational Education and Training Authority, the Muhimbili University College for Health Sciences, the Southern African Extension Unit, the Institute of Adult Education, and the Co-operative College Moshi. These organizations enrol over 18,000 students between them. In addition to more traditionally expected roles for open and distance learning (such as higher education or providing schooling to adults), there are various innovative applications of distance education. These include educating Burundian refugees, training local counsellors, and offering civic education (UNESCO, 2002).

Technological development and advances in the information and communication technology (ICT) have opened up new possibilities and opportunities in open and distance education. The increasing number of open universities being established across the world is highly indicative of this trend. Similarly, more and more traditional universities are transforming from single mode to dual mode universities, recognizing the importance of distance education in providing greater accessibility and up-to-date educational resources. This paper is therefore written to visualize the way possible through which open and distance education can reach the whole society and much attention paid to the vulnerable and disadvantaged groups, the way of delivering resources and cases of quality assurance.

\subsection{Definition of Key Terms}

\subsubsection{Open education resources}

Open Educational Resources (OERs) are defined as technological enabled, open provision of electronic educational materials for consultation, use and adaptation by a community of users for non-commercial purposes. They are typically made freely available over the web or the internet (Atkins, Brown and Hammond, 2007). Their principle use is by teachers and educational institutions to support course development, but they can also be used directly by students. Open educational resources include learning objects such as lecture material, references and readings, interactive materials such as simulations, role play, video, assessment tools, research articles, databases, experiments and demonstrations, as well as syllabuses, curricula, and teachers'/learners' guides (UNESCO, 2011). Open educational resources should be in the form of self-instructional material which is always based on sound instructional design principles (namely it should be learner-friendly, use simple language, and include interactive learning activities and feedbacks). The material may be in various forms: printbased, web-based and or multimedia (MQA, 2011).

\subsubsection{Open and distance learning}

Open and distance learning is a field of education that focuses on teaching/learning methods and technology with the aim of fostering teaching and learning processes, often on an individual basis, to students who are not physically present in a traditional educational setting such as a classroom. It has been described as a process to create and provide free access to electronic learning resources when the source of information and the learners are separated by time and distance, or both. The programme aims at bridging the time, geographical, economic, social and educational and communication distance between student and institution, student and academics, student and courseware and student and peers (MQA, 2011). Among the more commonly used terms related to open and distance learning are the following: correspondence education, home study, independent study, external studies, continuing education, distance teaching, adult education, technology-based or mediated 
education, learner-centered education, open learning, open access, flexible learning, and distributed learning.

\subsubsection{Quality assurance}

Quality is generally defined in different perspectives. One simple meaning of 'quality' is in terms of the customer's satisfaction with a product, or its fitness for its particular purpose. It can usually be constructed and interpreted in terms of excellence, consistency, and achievement of specified standards. In this context, we would be discussing the definition of quality being used with regard to the products within a distance education institution which is a producer of a large number of self-learning materials and a service provider. It is also a producer of programmes courses related products such as units, blocks, books and videos, CD-ROMs, which have to adhere to specified quality measures and of a service. This provision covers counselling, tutorials, assessments and degree or diploma/certificate awards, and the distance education system needs to know and to be able to measure the quality of its products and services. In a simple way we can say that quality is not synonymous with excellence. It indicates the management of continuous process aimed at bridging the gap between the expected effect (what ought to be learned) and the actual effect (what has been learned) (UNESCO, 2002 and MQA, 2011).

\subsubsection{ICT and e-learning}

Information and Communications Technology (ICT) refers to forms of technology that are used for communication and to transmit, store, create, share or exchange information. This broad definition of ICT includes technologies such as: radio, television, telephone (both fixed line and mobile), computer and network hardware and software, satellite systems and so on, as well as the various services and applications associated with them, such as video conferencing and distance learning. E-learning comprises all forms of electronically supported teaching and learning resources. E-learning services have evolved since computers were first used in education. However, a trend to move towards blended learning services is now becoming important, where computer-based activities are integrated with practical or classroom-based situations (UNESCO, 2002).

E-learning is benchmarked to learning that is facilitated and supported by means of Information and Communications Technology (ICT). E-learning is therefore defined as a broad set of applications and processes which include web-based learning, computer-based learning, virtual classrooms, and digital. Much of this is delivered via the internet, intranets, audio and videotape, satellite broadcast, interactive TV, and CD-ROM. The definition of e-learning varies depending on the organization and how it is used but basically it involves electronic means of communication, education, and training. Many terms have been used to define e-learning in the past. For example web-based training, computer-based training or web-based learning, and online learning are a few synonymous terms that have over the last few years been labelled as e-learning (Butcher, 2009).

Information and Communication Technologies (ICTs) are generally accepted as a modern instrumental tool that enables the educators to modify the teaching and learning strategy they use in order to increase students interest. Its general definition covers any product that will store, retrieve, manipulate, transmit or receive information electronically in a digital form. It consists of hardware, software, networks and media for collection, storage, processing, transmission and presentation of information (voice, data, texts and images) (Mbaeze, et, al., 2010).

\subsubsection{Vulnerable and disadvantaged groups}

The word disadvantaged is a generic term for individuals or groups of people who face special problems such as physical or mental disability, lack money or economic support, are politically deemed to be without sufficient power or other means of influence. The disadvantaged group is often applied in a third world context and typically relate to women with reduced upward mobility exclusion and having limited access to natural resources, services and economic opportunities. They are often landless or marginal farmers operating on the most unproductive land. Statistically a person born into poverty is likely to die there and have children who live powerless as well. In terms of education, disadvantaged group refers to those whom have the right to education but with regard to the special problems faced, they become vulnerable (at risk) to the service.

\section{Delivery of Basic and Continuing Education through Open and Distance Learning}

The government of the United Republic of Tanzania realizes the fact that quality education is the pillar of national development, for it is through education that the nation obtains skilled manpower to serve in various sectors in the nation's economy. It is through quality education Tanzania will be able to create a strong and competitive economy which can effectively cope with the challenges of development and which can also easily and confidently adapt to the changing market and technological conditions in the region and global economy.

The structure of the formal education and training system in Tanzania constitutes 2 years of preprimary education, 7 years of primary education, 4 years of junior secondary (ordinary level), and 2 years of senior secondary (advanced level) and up to 3 or more years of tertiary education. Specifically, the education 
system has three levels, namely: basic, secondary and tertiary levels. Basic or first level education (which is compulsory to every one) includes pre-primary, primary and non-formal adult education. Secondary or second level education has ordinary and advanced level of secondary schooling while tertiary or third level includes programmes and courses offered by non-higher and higher education institutions ${ }^{1}$

Two ministries manage and co-ordinate the education sector, namely Ministry of Education and Vocational Training (MoEVT) and Higher Education. The MoEVT includes a number of semi-autonomous agencies: Agency for Development of Educational Management (ADEM), Institute of Adult Education (IAE), National Examinations Council of Tanzania (NECTA), Tanzania Institute of Education (TIE), Tanzania Library Services Board (TLSB), and Vocational Education and Training Authority (VETA). However, the Ministry of Regional Administration and Local Government also manages basic education. At tertiary level, planning and service delivery are vested with the institutions themselves through their governing councils. Nevertheless, coordination and quality control is the responsibility of the Higher Education Accreditation Council (HEAC). At primary and secondary levels quality assurance remains to be the responsibility of school heads, district or municipal education office, ward education office and school inspector ${ }^{2}$

Basic education in Tanzania has been and is being delivered traditionally, where most of the time teacher centered approach is commonly practiced with a little of student centered strategy. Few years back around 70's - 80's basic education programmes were delivered to learners' countrywide using interactive radio instruction in schools. The Radio Tanzania Dar es Salaam (RTD) which today is the National Tanzania Broadcasting Company (TBC - 'Taifa') it was used to broadcast programmes related to basic education all over the country. Nowadays there are a number of community based radio broadcasting stations to most areas of the country, just to mention few of them; Radio Orkonorei in Simanjiro, Fadeco in Ngara and Radio Sengerema in Sengerema. This programme broadcasted through radios can be able to reach out-of-school learners who have no basic education, nor the ability to access the formal school system due to inadequate provision or insufficient facilities, poverty, distance to the nearest formal - government school, increasing parental disinterest in school education, orphans and the impact of HIV/AIDS. There should be enough facilities and mentors or teachers to assist the learning process through community radios or government and non-government broadcasting organizations. This kind of teaching and learning process is no longer practiced, although none or little research has been done to find the pros and cons of the programme.

Advancement in technology has opened a new approach to teaching and learning process of which a similar resource from one subject expert or group of subject experts can reach all through the modernized facilities like the audio and video cassettes, CDs, DVDs, satellite broadcasting, online distribution of content and information via corporate websites, moodling and mapping. The government has to ensure or establish centers at district, municipals and ward levels where important infrastructures like computers with well internet connections, televisions, tape recorders, video cameras and radios are available to facilitate the process of teaching and learning. It is through these centers where learners from different areas, including all with geographical isolation, physical disabilities and disadvantaged groups can have access to the learning resources from the nearby centers. The internet as a medium of learning is explored to the maximum for the creative use and positive impact of such knowledge on the teaching and learning processes. Topics from the syllabus can be integrated into web based structure where the subject experts prepares the learning materials and design a frame work with links to the internet through which learners is guided to allocated and make use of them (Mapping). Through internet search, the students acquire the latest know how on the assigned topics and compile the resources related to the given topic in the form of notes (Natarajan, 2005). However, learners who are remotely located and could not reach the centers can instead use radios, audio and video cassettes, CDs, DVDs to learn and in the presence of the mentor or subject expert.

A synchronous technologies such as web 2.0, blogs, social networking facilities and e-portfolios can be used effectively to support teaching and learning. Diverse and current technologies that will serve the institutions' educational mission and be sustainable will be included in the delivery of courseware. Technologies such as telephony, multimedia CDs and DVDs, video and audio conferencing, SMSs and MMSs via cell phones, e-mail and discussion forums/chat facilities via institutional webpage offer new possibilities for supporting innovative learning in distance education and must be integrated from the design phase of courseware. The multimedia approach with interactivity between students and lecturer(s), students and tutors, students and students, and student and institution is much more effective than a single medium (UNISA, 2008).

1 Tanzania education. (Online). Available www.tzonline.go.tz, February $08^{\text {th }}, 2012$

2 United Republic of Tanzania Ministry of Education and Vocational Training (MoEVT) Information \& Communication Technology (ICT) Policy for Basic Education: ICT for Improved Education. (Online) Available: www.moe.go.tz (February 08, 2012) 


\subsection{Web-Based Instruction (WBI)}

It is defined broadly as any form of innovative approach for delivering instruction to a remote audience in which the web is included as a tool. Presently, several web sites have been developed to provide learners with access to instructional resources from a distance. However, most course-based or learning sites simply post course materials. In such instances, use of the web falls far short of the potential this medium affords. According to UNESCO (2011), currently used web models of learning can be identified as one of the followings:

1. The web as source of information: This is the simplest use of the web. It is used as a convenient place to store supporting information for traditionally offered courses. There are varieties of search engines and subject based information gateways through which learners and facilitators can use to access the supporting teaching/learning resources like e-books and e-journals. Many institutions have moved to use the web to present information in a more structured way for teaching process. Students use the screen to read materials, activate multimedia demonstrations, and take self-correcting quizzes or other activities. The course material is mostly factual information, which is to be learned from the web page and any accompanying media. There is no interaction between teacher and the students through the web.

2. The web as a facilitator: Some web-based courses include some form of personal communication between students and other students via the use of email and perhaps chat rooms.

3. The web as a communication medium between the facilitator and students: In this context, students learn from the facilitator but through the web and not from the web. Thus, the web acts as the communication medium for the necessary interaction and thus mirrors a face-to-face learning environment, within which the students will be able to establish some form of human relationship with the facilitator (Natarajan, 2005).

Having all this in place and with high quality of tools and availability of other electronic infrastructures, enough knowledge and skills on interacting with the facilities will make flexibility in implementing distance learning. Learners will be advised to visit the nearby centers where access of the facilities and learning materials are available. The same resources should be prepared in different multimedia for effective learning to all. There are some areas where infrastructures don't support open and distance learning and thus the use of multimedia will overcome the challenge and at the same time alternative sources of electricity should be considered to such areas.

\subsection{Computer-Assisted Learning}

The established centers with all important facilities can as well support learning through use of computers. Important tools like CD-ROMs and video cameras for video conferencing need to be in place for computerassisted learning. The opportunities associated with the development of computer-based technology in contributing to effective science education have grown exponentially within the past decade. The multimedia software available on CD-ROM plays a powerful role with applications in laboratories and lectures, tutorials and project work (UNESCO, 2011).At the centres learners can learn theoretically and practically with an aid of computer and the associated tools mentioned earlier on. CDs and DVDs can be used to provide virtual laboratories through which details on the preparation, essential equipment or apparatus required, and method or procedures relevant to the practical can be demonstrated. In the end students can then actively perform experiments themselves based on the improvised simulation. Virtual laboratory presents a range of equipment on-screen and may offer a very high degree of interactivity. Training through audiovisual aids can play an important role in the fields of medical education, industrial processing, domestic sciences and natural science subjects. Teleconferencing is one of the most useful approaches for distance education combining satellite teleconferencing with hands on activity session. Its implementation requires; computers well connected to the internet, teleconferencing speakers, video or web cameras. The method can help for live interaction between students or subject facilitator and the student; it is good to apply when interviewing a student, online chatting and makes interactive call-in sessions and local sessions (Natarajan, 2005).

\section{ICT, E-learning and Open Education Resources}

The open and distance learning institution services through ICT and e-learning are a complex web of people, services and interactions. There are many individuals and groups that either use or provide learner support services. However, it is desired that any information system should need to be responsive to such diverse groups. In the open and distance learning system the students can log on to the databases of their institution and benefit from them in various ways e.g. be informed about the latest activities in their institution, navigate through one information topic to another, have an online status of different topics. To accomplish all these tasks successfully and efficiently, the web-system to be developed in the open and distance learning institutions must be provided with some specific provisions such as intelligent software agents for performing the required functions (Khanna and Basak, 2011). 


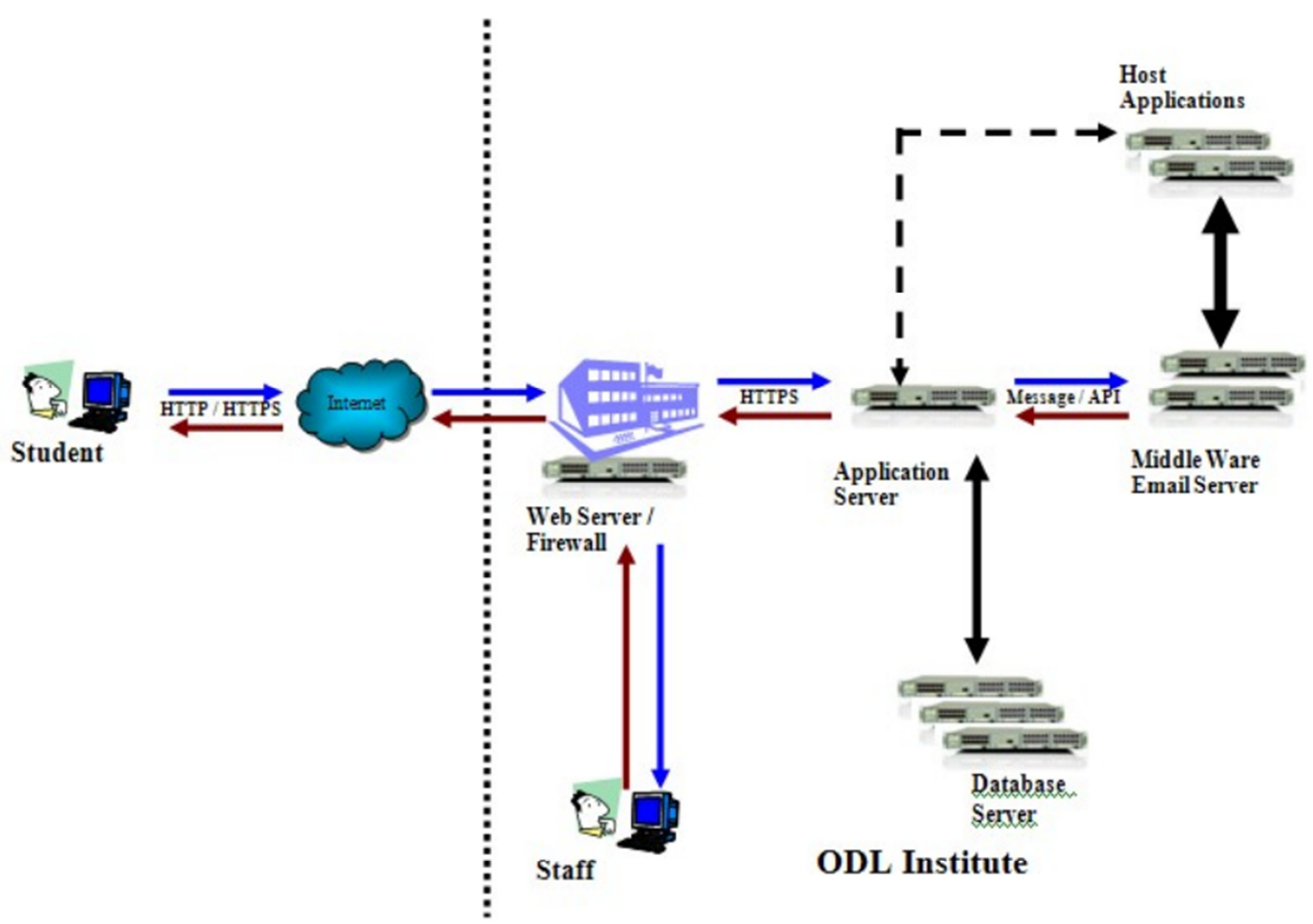

Figure 1. Web Infrastructure Architecture for Web Based Information System

Most of the education institutions around the world have been using the internet and other digital technologies to develop and distribute teaching and learning for decades. Recently, Open Educational Resources (OER) have gained increased attention for their potential and promise to obviate demographic, economic, and geographic educational boundaries and to promote life-long learning and personalized learning. The rapid growth of OER provides new opportunities for teaching and learning, at the same time, they challenge established views about teaching and learning practices (Yuan, et, al., 2010).

ICT support for learning communities has become common place over the last decade but not well developed to basic and secondary education. With tertiary education, there are usually various bottom-up initiatives, using different tools and educational designs to support learning and teaching. Recently, in many universities a broad variety of pioneering projects have been set in place, using ICT in various forms and formats, but with little or no strategic approach to sustainability. Thus, the need for e-learning strategy has been recognized. An e-learning strategy refers to a comprehensive set of goals and directives, elaborated and endorsed by institutional management, for the sustainable implementation of ICT support for learning and teaching. The Ministry of Education and Vocational Training and its agencies may need to find out the strategies used by the tertiary institutions to the success in using ICT and e-learning to advance the same at basic and secondary education (Arnold, 2010). However, learners at all levels of education should be well trained to develop skills on the use of ICT and e-learning in the process of teaching and learning. With the widespread availability of web 2.0 technologies including wikis, weblogs and social networking tools, the situation has become even more complex. There are a growing number of choices for creating digital habitats for learning communities. Web 2.0 technologies are usually easy to use, freely available and also suited to support informal learning settings and it covers a large geographical area, only that facilities and techno- know-how are challenges at meeting the learners' demand.

Streaming software is one of the tools which allows for easy digitizing of videotaped lectures. The tool makes it possible to broadcast live lectures to remote locations or to capture lectures for later revision by students. Thus, streaming technologies can provide students with flexible study formats while also reaching a wider audience, e.g. students with a disability or who are otherwise incapable of following lectures on campus or in a formal education system (Arnold, 2010).

Web based learning resources as educational tools offer learners access to well-structured and easilyupdatable study materials, task-based activities, online resources, and tutorial support. In spite of these benefits, however, learners may be left frustrated or disappointed; because web based learning resources do not sufficiently address their needs or expectations. Web based learning resources have been developed mainly by 
software designers and developers with a high level of technical expertise, but without knowledge about learners' needs. As a result, difficulties may arise when graphics is overemphasized to the detriment of pedagogical aspects, so that a web based learning resources looks attractive, but is difficult to use in educational settings. Clearly, existing web based learning resources still lack a number of important issues that need to be considered in design and evaluation (MQA, 2011).

Given the qualities and the weaknesses of the software designers, it calls an attention to the ministry of education and education agencies to have in mind of the software's shortcomings when designing web-based learning resources which will be uploaded to the educational websites or to the social networking tools for students. An independent educational website can be developed and a number of subject experts together with website developers and software engineers work together to have a genuine webpage for educational purposes to basic education system.

Developers need to design web based learning resources with suitable usability, and then tailor it more closely to meet the learners' needs. The resources lies in helping learners discover and explore things for themselves through interactive, flexible, differentiated, and motivating activities. Unfortunately, as mentioned above, most web based learning resources provide little support to achieve a high level of flexibility, interactivity, feedback, differentiation, and collaboration, diminishing the added value and indisputable character of web based learning resources. The ministry of education and vocational training and its educational agencies should establish a quality assurance unit, through which the educational curriculum developers will constitute the unit and have a role of monitoring and evaluating the quality of web based resources. However, there should be a routine of evaluating students' and teachers' perceptions of web based learning resources in open and distance education, modalities of teaching and learning using these resources (Hadjerrouit, 2010).

\section{Open and Distance Learning for Vulnerable and Disadvantaged Groups}

Open and distance learning has opened a new era to vulnerable and disadvantaged groups, as despite the problems they are facing and particularly on social responsibilities, economic status, and disabilities yet they can be able to learn at different levels of education. Agyemang and Dadzie (2010) noted that with application of ICT and e-learning a stronger distance learning approach can increase educational access by reaching out the disadvantaged groups, including: the less fortune primary education who did not attend school for some reasons like being a refugee or orphans of which they can have access to this education through open and distance learning. The centers where the victims are located can be improvised with ICT facilities and IT professionals and subject experts or mentors for making effective learning.

Open and distance education also helps secondary school graduates who fail to gain admission to university, they can just enroll for distance learning through the institution that offers degree programmes in that nature like as it is being done by the Open University of Tanzania (OUT). Also, women with household responsibilities, it is estimated that currently women comprise 35 per cent of tertiary enrolments in Africa. This under-representation implies for an increase in the general intake, as home-based study within a flexible schedule is well suited for those who must also fulfill family responsibilities. Again learners in remote rural areas, small towns or refugee camps who do not have convenient access to tertiary institutions will save travel time, travel expenses, as well as the continuation of income while studying. For example, it has been noted that since 1994 refugees from Burundi who lived in camps in western Tanzania could enroll for courses in basic english, as well as mathematics, history, geography and swahili (Agyemang and Dadzie, 2010).

Social and political tension can displace the society and become vulnerable to different circumstances and thus in the end find open and distance learning as the only means of access to education. Open and distance learning provides an opportunity to all levels of education to the people with disabilities. The main role of the ministry is to ensure that the centers or institutions which provide education services through open and distance learning are improvised with facilities that are friendly-user to this group with regard to the type of physical disability.

\section{Quality Assurance for Open and Distance Learning}

Quality assurance measures are seen as quality and security-enhancing measures. Today open and distance education has developed multi-typologies, according to the specific needs and aspirations of learners. It aims to serve as an alternative mode of educational delivery. It is now evident that points of interrogation on quality assurance addressed to distance education courses are equally applicable to traditional measures of quality assurance, such as quality of curriculum design, instructional materials, assessment, learner's satisfaction with products and services, independent, external and technical reviews, evaluation and validation. The open and distance education institutions believe that its continuing commitments to access and equity, learner independence, and professional design relevance demand a flexible and interactive approach to curriculum and modes of teaching. These institutions are now moving towards a stage in which learning is an individual process. Due to this approach, quality assurance has to develop a range of control mechanisms and assurance processes 
which cater equally to all its media and modes of teaching and learning (MQA, 2011).

A Quality Assurance System (QAS) consists of the policies, attitudes, actions and procedures necessary to ensure that quality is being maintained and enhanced. Quality assurance system should be applied to the courses and programmes offered and the learning content, the staff, technology, learning methods and services. Quality assurance denotes those practices in distance education which lead to some kind of public, formal guarantee or certification, so quality assurance is typically a matter of judging the outcome of the implementation of course material, a special performance, or testing exercise (UNESCO, 2002).

In the domain of distance education quality assurance includes the course-approval mechanisms, team work for preparing materials, processes of designing the material and the reviews of the material, which are subject to scrutiny either in the form of student questionnaires, or by the review of external experts. The findings of the formal procedures are usually publicly announced or at least made available to the practitioners. In this way quality assurance is an ongoing process and is public and formal in its nature. In general, quality assurance is defined as the process whereby standards are specified for a product or service and steps are taken to ensure that these standards are met substantially (Butcher, 2009).

The quality of the academic staff in open and distance learning is one of the most important components in assuring the quality of that mode of distance education. Thus, every effort must be made to establish proper and effective recruitment, service, development and appraisal policies that are conducive to staff productivity. It is important that every programme has appropriately qualified and sufficient number of academic staff. The institution should consider various responsibilities and specialised tasks that would be required for the open and distance learning academic staff, for example; knowledge in pedagogy, IT-related technical skills and student support. However, teaching, research, consultancy services and community engagement are the core interrelated academic activities (MQA, 2011).

The physical facilities to support an open and distance learning programme are slightly different from facilities for face to-face programmes. For open and distance learning, learning centers are needed to cater for students that are spread over a wide geographical area. A learning center (district, municipal or at ward level) would have a minimum requirement in terms of infrastructure and facilities. Other facilities which are essential for supporting teaching-learning activities in open and distance learning such as electronic learning platform, virtual library and counselling system through distance are equally important. The programme must have quality, sufficient and appropriate physical facilities and educational resources to ensure its effective delivery. ICT and related facilities for example, learning management system, digital or virtual library, video conferencing, virtual laboratories, online helpdesk must be provided for and maintained up to acceptable current standards and capacities. The library or resource center must have adequate and up-to-date reference materials and qualified staff that meet the needs of the programme and research amongst academic staff and students. These include provisions for adequate computers, and information and communication technology mediated reference materials. For practical-based programmes, equipment and facilities for training must be adequately provided for at all learning centers (OECD, 2007).

For research-based programmes and programmes with a substantial research component, the ministry or institution must provide adequate and suitable research facilities and environment. Must also have a policy regarding the selection and effective use of electronic devices, internal and external networks, and other effective means of using information and communication technology in the programme; this includes coordination with the library services. The learning environment should be regularly improved through renovations, building new facilities and the acquisition of the latest and appropriate equipment to keep up with the development in educational practices and changes (Yuan, et, al., 2010).

The educational resources, services and facilities should be periodically reviewed to assess the quality and appropriateness for current education and training. The facilities should be user-friendly including those with special needs, vulnerable and disadvantaged groups. Quality enhancement calls for programmes to be regularly monitored, reviewed and evaluated. These include the monitoring, reviewing and evaluation of institutional structures and processes (Butcher, 2009). Monitoring and review for open and distance learning programme should encompass elements such as the open and distance learning system or structure, learning materials, delivery system, communication system, student support services, financial strength, assessment system, teaching strategies and physical facilities. Programme monitoring and review activities should involve all academic and non-academic staff and students. These activities involve the process of gaining feedback from all relevant stakeholders. The findings should be recorded, reviewed and evaluated. Furthermore, actions should be taken on the findings with the purpose of enhancing all aspects of the programme.

\section{Conclusion}

Addressing the issue of access to quality education is a matter of urgency, and yet the formal education system has not tended to provide education for all at all levels. For out-of school learners, disadvantaged groups and at tertiary education, therefore, open and distance learning strategies need to be adopted by the government and 
institutions at ensuring that open and distance learning is considered as an alternative approach at addressing the educational needs. The out of school learner's and particularity the under 18 years of age are the most vulnerable group that has their child rights violated. The challenge is how to develop suitable programs and high quality learning materials to protect child rights and retain them in the education system than drop outs. Thus, it is crucial take into consider child rights, adult learners, vulnerable and disadvantaged groups when planning, designing, developing and implementing education programmes for the purpose of reaching all through open and distance learning. However, there should be effective quality assurance systems for the programme, and the services provided need to be user-friendly to the vulnerable and disadvantaged groups and particularly those with disabilities.

\section{References}

Agyemang, K., and Dadzie, P. (2010). Providing Information Communication Technology Support to Distance Education Students: A Case of the University of Ghana, Legon, Ghana: University of Ghana.

Atkins, D.E., Brown, J.S., and Hammond, A.L. (2007). A Review of the Open Educational Resources (OER) Movement: Achievements, Challenges, and New Opportunities. (Online) Available: http://www.hewlett.org/uploads/files/. (January $23^{\text {rd }}, 2012$ ).

Arnold, P. (2010). Open Educational Resources or Closed Learning Management Systems? -The Challenge of Designing ICT Support for Learning Communities in Higher Education. Journal of Community Informatics, Vol 6, No. 3, (2010), Germany: University of Applied Sciences Munich.

Butcher, N. (2009). Open Educational Resources and Higher Education. South Africa: SAIDE publishers.

Hadjerrouit, S. (2010). A Conceptual Framework for Using and Evaluating Web-Based Learning Resources in School Education: Journal of Information Technology Education Volume 9, 2010. University of Agder, Kristians and Norway.

Khanna, P. and Basak, P. (2011). An Integrated Web-based Information System for Open and Distance Learning: Journal of Information Technology Impact Vol. 11, No. 2, pp. 153-168, 2011. India: Indira Gandhi National Open University.

Malaysian Qualifications Agency, (MQA), (2011). Guidelines to Good Practices: Open and Distance Learning. Malaysia: Higher Education office Publishers.

Mbaeze, I. C., Ukwandu, E., and Anudu, C. (2010). The Influence of Information and Communication Technologies on Students' Academic Performance. Journal of Information Technology Impact Vol. 10, No. 3, pp. 129-136, 2010. Nigeria: Evan Enwerem University.

Natarajan, M. (2005). Innovative Teaching Techniques for Distance Education. New Delhi - India: Satsang Vihar Marg Publishers

Ololube, N.P., Ubogu, A.E., and Egbezor, D.E. (2007). ICT and Distance Education Programs in a Sub-Saharan African Country: A Theoretical Perspective, Journal of Information Technology Impact Vol. 7, No. 3, pp. 181-194, 2007. Nigeria: University of Port Harcourt.

Organisation for Economic Co-operation and Development (OECD), (2007). Giving Knowledge for free: The Emergence of Open Educational Resources Centre for Educational Research and Innovation. Paris: France.

Thomas, G.M. (1995). Education-Past, Present, Future. In D.R. Walling, ed. At the Threshold of the Millennium, Bloomington, Indiana: Phi Delta Kappa

UNESCO, (2002). Open and Distance Learning: Trends, Policy and Strategy Considerations, France: Division of Higher Education.

UNESCO, (2011). Guidelines for Open Educational Resources (OER) in Higher Education, Commonwealth of Learning Publishers.

University of South Africa (UNISA), (2008). Open Distance Learning Policy. University of South Africa: University Press.

Yuan L., McEill, S., and Kraan, W. (2010). Open Educational Resources - Opportunities and Challenges for Higher Education, Cape Town: JISC and CETIS Publishers. 
The IISTE is a pioneer in the Open-Access hosting service and academic event management. The aim of the firm is Accelerating Global Knowledge Sharing.

More information about the firm can be found on the homepage:

http://www.iiste.org

\section{CALL FOR JOURNAL PAPERS}

There are more than 30 peer-reviewed academic journals hosted under the hosting platform.

Prospective authors of journals can find the submission instruction on the following page: http://www.iiste.org/journals/ All the journals articles are available online to the readers all over the world without financial, legal, or technical barriers other than those inseparable from gaining access to the internet itself. Paper version of the journals is also available upon request of readers and authors.

\section{MORE RESOURCES}

Book publication information: http://www.iiste.org/book/

Academic conference: http://www.iiste.org/conference/upcoming-conferences-call-for-paper/

\section{IISTE Knowledge Sharing Partners}

EBSCO, Index Copernicus, Ulrich's Periodicals Directory, JournalTOCS, PKP Open Archives Harvester, Bielefeld Academic Search Engine, Elektronische Zeitschriftenbibliothek EZB, Open J-Gate, OCLC WorldCat, Universe Digtial Library, NewJour, Google Scholar

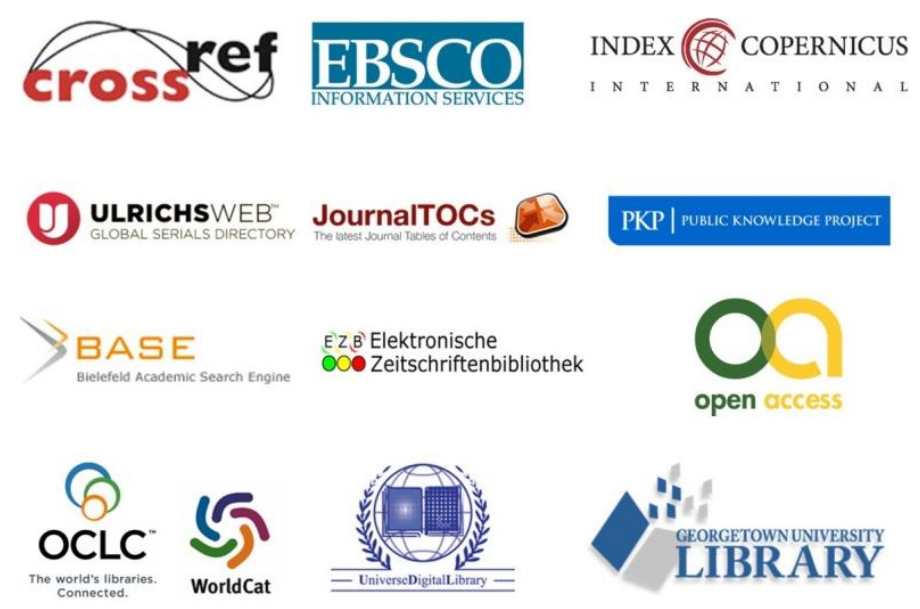

